\title{
Prediction of the rate of children prone to diphtheria infection in a Laos remote area: A reappraisal on seroepidemiology data during a major diphtheria outbreak in 2012
}

\author{
Wiwanitkit $\mathbf{S}^{1^{*}}$, Wiwanitkit $\mathrm{V}^{1,2}$ \\ ${ }^{1}$ Wiwanitkit House, Bangkok Thailand. \\ ${ }^{2}$ Honorary professor, Dr DY Patil University, Pune, India.
}

\begin{abstract}
Dear Editor,
Diphtheria is a preventable infection caused by Corynebacterium diphtheriae. This disease can cause severe respiratory tract problems in affected children. At present, this disease is still encountered in poor developing countries with poor sanitation backgrounds. In 2012, a major outbreak of diphtheria occurred in Indochina. The disease was also diagnosed in remote areas of Laos and Thailand [1 - 3]. Another diphtheria outbreak occurred in South Africa in 2015 [4]. Among the great considerations for each diphtheria outbreak are usually the availability, quality and the coverage of the vaccine. Hence, the data from epidemiology surveillance and records in each setting are useful for the assessment of diphteria situation in each area. Here, we performed a reappraisal on seroepidemiology data from 2012 diphtheria outbreak in Laos and tried to predict the rate of children prone to diphtheria infection in that country.

We used a mathematical model study using the locally available data on the diphtheria outbreak in Laos. The protocol was the same as the one which had been used in a previous report by Joob and Wiwanitkit [5]. The available published data from a previous seroepidemiology study in Laos was used as the primary data [5]. Briefly, the mathematical model was based on the standard joint probability mathematic principle. To predict the rate of diphtheria infection among children in that area, the following formula was used: " 1 - (diphtheria vaccine coverage rate $\times$ diphtheria vaccine efficacy rate)" and the final calculated prone rate was presented as a percentage. Based on the available data [3], the diphtheria vaccine coverage rate and diphtheria vaccine efficacy rate were equal to $59.8 \%$ and $83.6 \%$, respectively. The final calculated rate for the children prone to diphtheria in that remote area of Laos was equal to $50.01 \%$.

Laos is a poor tropical country in Indochina (Southeast Asia) where several tropical infectious diseases such as diphtheria, are presently endemic. According to a recent report [3], it has been noted that both problems of diphtheria vaccine coverage and its effectiveness are important factors leading to the outbreak. In the present study, we performed a mathematical model prediction to
\end{abstract}

*Corresponding Author: Somsri Wiwanitkit, Wiwanitkit House, Bangkok Thailand.

Email: somsriwiwan@hotmail.com

Tel/Fax: (+66) 24132436 measure the rate of diphtheria infection among children in a remote area of Laos. Our results indicated that more than half of the local pediatric population in that remote area (restricted to Houaphan Province) is prone to diphtheria infection. This is considered as a serious public health problem that should be managed. In conclusion, the high rate of diphtheria infection among children in remote areas of Laos implies an urgent need for public health implementation against diphtheria in this tropical setting.

\section{CONFLICT OF INTEREST}

The authors declare that they have no conflict of interest.

\section{REFERENCES}

1. Wanlapakorn N, Yoocharoen P, Tharmaphornpilas P, Theamboonlers A, Poovorawan Y. Diphtheria outbreak in Thailand, 2012; seroprevalence of diphtheria antibodies among Thai adults and its implications for immunization programs. Southeast Asian Journal of Tropical Medicine and Public Health. 2014;45(5):1132.

2. Sein C, Tiwari T, Macneil A, Wannemuehler K, Soulaphy C, Souliphone $\mathrm{P}$ et al. Diphtheria outbreak in Lao People's Democratic Republic, 20122013. Vaccine. 2016;34(36):4321-6.

3. Nanthavong N, Black AP, Nouanthong P, Souvannaso C, Vilivong K, Muller CP et al. Diphtheria in Lao PDR: insufficient coverage or ineffective vaccine? PLoS One. 2015;10(4):e0121749.

4. Mahomed S, Archary M, Mutevedzi P, Mahabeer Y, Govender P, Ntshoe $\mathrm{G}$ et al. An isolated outbreak of diphtheria in South Africa, 2015. Epidemiology \& Infection. 2017;145(10):2100-8.

5. Joob B, Wiwanitkit V. Rate of children at Thailand-Myanmar border area prone to tuberculosis infection: An epidemiological prediction with referencing to bacillus Calmette-Guerin vaccination in Thailand. Biomedical and Biotechnology Research Journal (BBRJ). 2019;3(1):42. 